\title{
Influence of Voltage Variation on the Size of Magnetite Nanoparticles Synthesized by Electrochemical Method
}

\author{
Ishu Singhal $^{1 *}$, Rohtash Kumar ${ }^{1,2}$ and Balaji Birajdar ${ }^{1}$ \\ 1. Special Centre for Nano Sciences, Jawaharlal Nehru University, New Delhi 110067, India \\ 2. School of Physical Sciences, Jawaharlal Nehru University, New Delhi 110067, India
}

\begin{abstract}
Present research deals with the synthesis of highly pure, large scale, economical and mono-dispersed magnetite nanoparticles by using electrochemical method at a low temperature of $80{ }^{\circ} \mathrm{C}$. We have tried to indigenously develop two-electrode electrochemical cell which was later used to synthesize Iron oxide nanoparticles with different size ranges by varying different parameters. The setup brings up the oxidation of the anode and reduction of the cathode. $\mathrm{NaCl}$ was used as an electrolyte. For each of the sample obtained, the structural investigation was carried out by measuring XRD (X-ray diffraction). The morphology was studied using SEM (Scanning electron microscopy) and TEM (Transmission electron microscopy). Elemental composition was verified using energy dispersive X-ray spectroscopy (SEM-EDX).
\end{abstract}

Key words: Electrochemical, magnetite, nanoparticles, $\mathrm{Fe}_{3} \mathrm{O}_{4}$, electrolyte.

\section{Introduction}

Magnetite nanoparticles have drawn a lot of attention due to their good biocompatibility, super-paramagnetism, and applications in hyperthermia, cancer cell therapy [1-3], and so on. Also magnetite has been already used in bulk industrial production processes as catalysts for alcohol oxidation and $\mathrm{NH}_{3}$ production [4-6], in wastewater purification $[7,8]$ and as pigment and related industries [9]. In natural state, sixteen pure phases of iron oxide are known to mankind till date [10]. Due to their small size, they exhibit different electrical, chemical, magnetic and optical properties from the bulk materials [11]. Shape and size strongly affects the dispersibility in various solvents and properties exhibited by magnetite nanoparticles.

Therefore, researchers are trying to explore economical, easy and reproducible methods for synthesizing $\mathrm{Fe}_{3} \mathrm{O}_{4}$ nanomaterials. Synthesis of iron oxide nanoparticles through co-precipitation method is

\footnotetext{
*Corresponding author: Ishu Singhal, research fields: nanotechnology, magnetic nanoparticles and nanobiotechnology.
}

quite difficult due to the instantaneous nature of this reaction which makes it difficult to control the nucleation process [12]. Some of the prominent methods currently used by researchers are: hydrothermal [13, 14], wet-milling [15], sol-gel [16], pyrolysis [17], electrochemical [18, 19], etc. Among these, electrochemical method is the most promising but not exhaustively researched method for the synthesis procedure. For example, the precise influence of various parameters such as voltage, temperature, electrolyte, electrode spacing, ripples factor, stirring rate affecting the nucleation process, on the growth of $\mathrm{Fe}_{3} \mathrm{O}_{4}$ nanoparticles is not fully understood yet.

In the present study, we have synthesized magnetite nanoparticles by electrochemical process using two-electrode system. We have tried to find out the effect of voltage on the particle morphology and size of magnetite nanoparticles. A preliminary hypothesis concerning the reaction mechanism during two electrode electrochemical synthesis of $\mathrm{Fe}_{3} \mathrm{O}_{4}$ nanoparticles is also proposed. All the results and data such as crystal structure, morphology, particle size and elemental composition were investigated using, XRD 
(X-ray diffraction), SEM (Scanning electron microscopy), EDX and TEM (Transmission electron microscopy) for each prepared sample.

\section{Experiment}

\subsection{Synthesis Procedure}

Electrochemical studies were carried out in our indigenously developed classical two electrode electrochemical cell (Fig. 1). Pure iron electrodes in the form of cylindrical rods with a diameter of $10 \mathrm{~mm}$ and length of $70 \mathrm{~mm}$ were used to form anode and cathode. The experimental cell was housed in a conventional $250 \mathrm{ml}$ borosil glass beaker. The electrodes were first kept in dilute nitric acid $\left(\mathrm{HNO}_{3}\right.$, Merck) for $30 \mathrm{~min}$ to clean and remove the oxide layer already present. Then they were polished with zero number sandpaper and further cleaned and sonicated in ethanol for $5 \mathrm{~min}$ before the commencement of experimental run. After drying of the electrodes, they were spaced $4 \mathrm{~cm}$ apart and fixed to keep the distance between electrodes constant.

Two samples were prepared under varied voltages keeping other parameters as same. The electrolyte solution was prepared by adding $2 \mathrm{M}$ sodium chloride ( $\mathrm{NaCl}, \mathrm{Merck})$ in double distilled de-ionized water. As such no capping agent was used. $200 \mathrm{ml}$ of double distilled de-ionized water was taken as the medium for

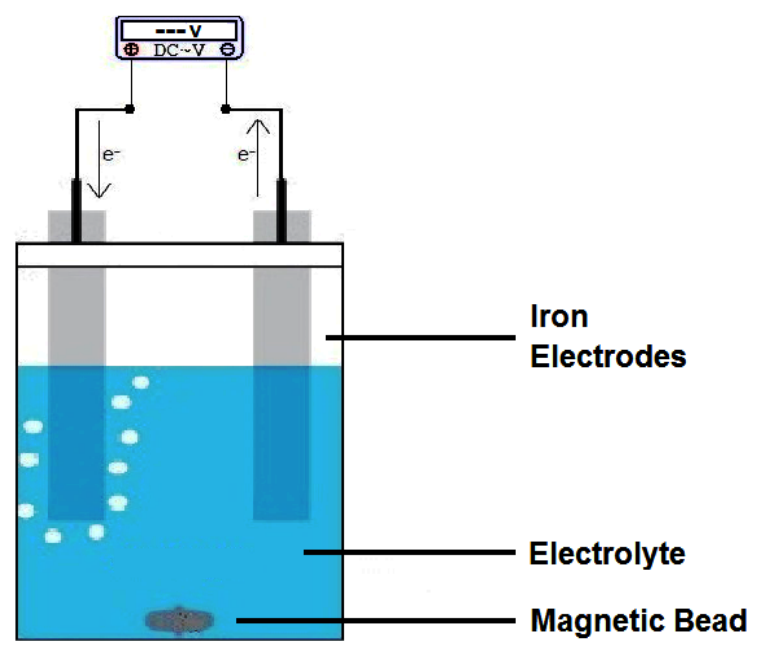

Fig. 1 Schematic diagram of our electrochemical cell. electrolyte cell to operate. Electrochemical cell was operated at a voltage of $4 \mathrm{~V}$ Direct Current (DC) and 2 $\mathrm{V}$ DC under controlled and careful stirring. The samples were named as A for $2 \mathrm{~V} \mathrm{DC}$ and $\mathrm{B}$ for $4 \mathrm{~V}$ DC.

After few minutes of operation, the electrolytic solution changed its color to yellow-brown solution before turning into black precipitate. The experimental run was carried out for 15 min and kept separately for further processing. After the experimental run, the precipitate obtained was washed and purified several times using ultracentrifugation and decantation method to achieve powder sample for further characterization.

\subsection{Structural Characterization}

For each of the sample obtained, crystal structure investigation was carried out by measuring X-ray diffraction using Rigaku MiniFlex ${ }^{\mathrm{TM}}$ II benchtop XRD system with $\operatorname{CuK}_{\alpha}(\lambda=1.54 \AA)$ radiation source. For $\mathrm{XRD}$, powdered sample were used for both the samples. Their surface morphology and particle size was analyzed using scanning electron microscopy (Zeiss SEM for sample A and Mira 3 Tescan SEM for sample B) and transmission electron microscopy (JEM-2100F with an operating voltage of $150 \mathrm{kV}$ for sample A only). Elemental composition was verified using energy dispersive X-ray spectroscopy (EDX integrated system with Zeiss EVO 40). Samples for SEM-EDX were prepared by dropping few drops of solution containing iron oxide nanoparticles upon a silicon substrate. Then the substrate was heated for 15 min to obtain a thin film. This prepared sample was further coated with a conductive thin film $(<2 \mathrm{~nm})$ of gold. Samples for TEM were prepared by adding a drop of solution containing cupric oxide nanostructures to a circular carbon coated copper TEM grid. Then the as prepared grid was kept under IR lamp to dry.

\section{Results}

\subsection{X-Ray Diffraction}

X-Ray Diffractogram of sample A and B are shown 
in Fig. 2. Powder XRD data of the specified compositions were compared with JCPDS Card 075627. They fit well with magnetite structure with a space group Fd-3m (227). Both the powdered samples display cubic system with face-centered lattice.

\subsection{Scanning Electron Microscopy}

Secondary electron images of sample A (Fig. 3) and sample B (Fig. 4) revealed mono-dispersed spherical nanoparticles with an average particle size of $50 \mathrm{~nm}$ for low applied voltage $(2 \mathrm{~V})$ whereas for high applied $100 \mathrm{~nm}$. SEM-EDX spectra of sample A and B are shown in Figs. 5a and 5b, respectively. Both of these spectra show Fe-K and $\mathrm{O}-\mathrm{K}$ peaks. The Au peak at $2.2 \mathrm{KeV}$ arises due to the gold coating.

\subsection{Transmission Electron Microscopy}

The TEM bright field images at low and higher magnification are shown in Fig. 6a and $6 \mathrm{~b}$ respectively. They reveal nearly spherical nanoparticles with an average particle size in the range of 30 to $50 \mathrm{~nm}$ for low applied voltage (2 V DC) sample A in agreement with the SEM imaging. The corresponding selected area diffraction pattern (Fig. 6c) reveals 220, 311, 400 and 440 rings of magnetite structure. High resolution TEM image (Fig. 6d) of magnetite nanoparticles reveals voltage $(4 \mathrm{~V})$ the average particle size comes out to be

$0.27 \mathrm{~nm}$ lattice spacing.

\section{Discussion}

Synthesis of pure and highly mono-dispersed $\mathrm{Fe}_{2} \mathrm{O}_{3}$ nanoparticles have been quite interesting task among research workers. In the present study, it has been shown that during the dissolution of iron electrode in

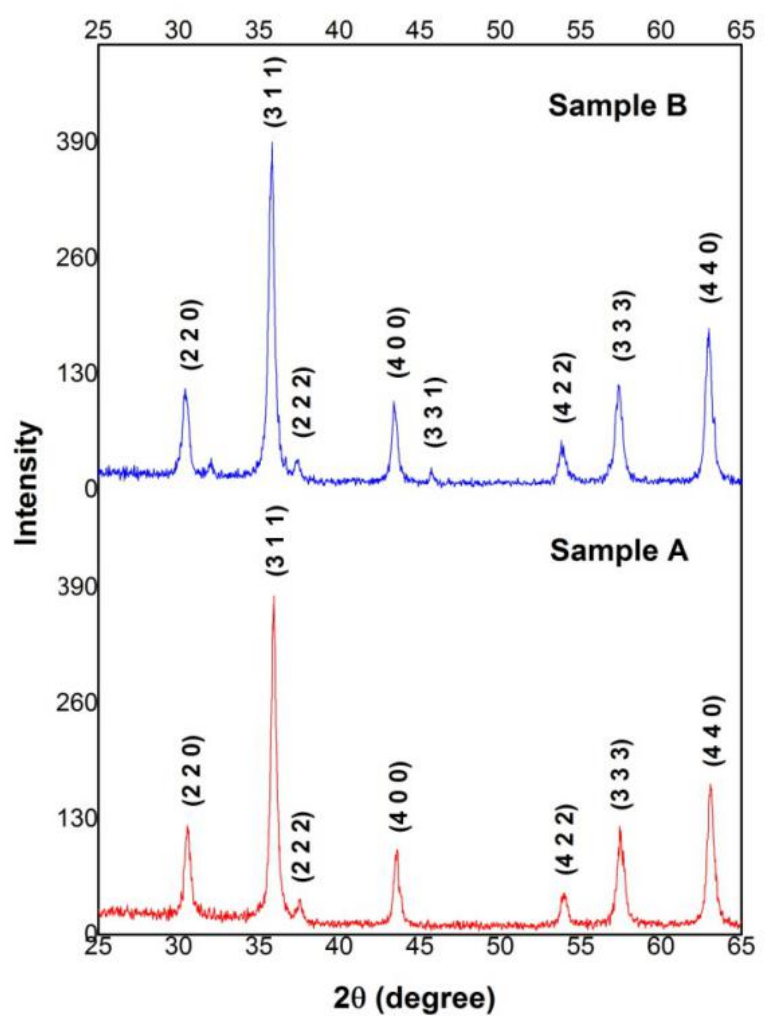

Fig. 2 X-ray diffractogram of sample A.

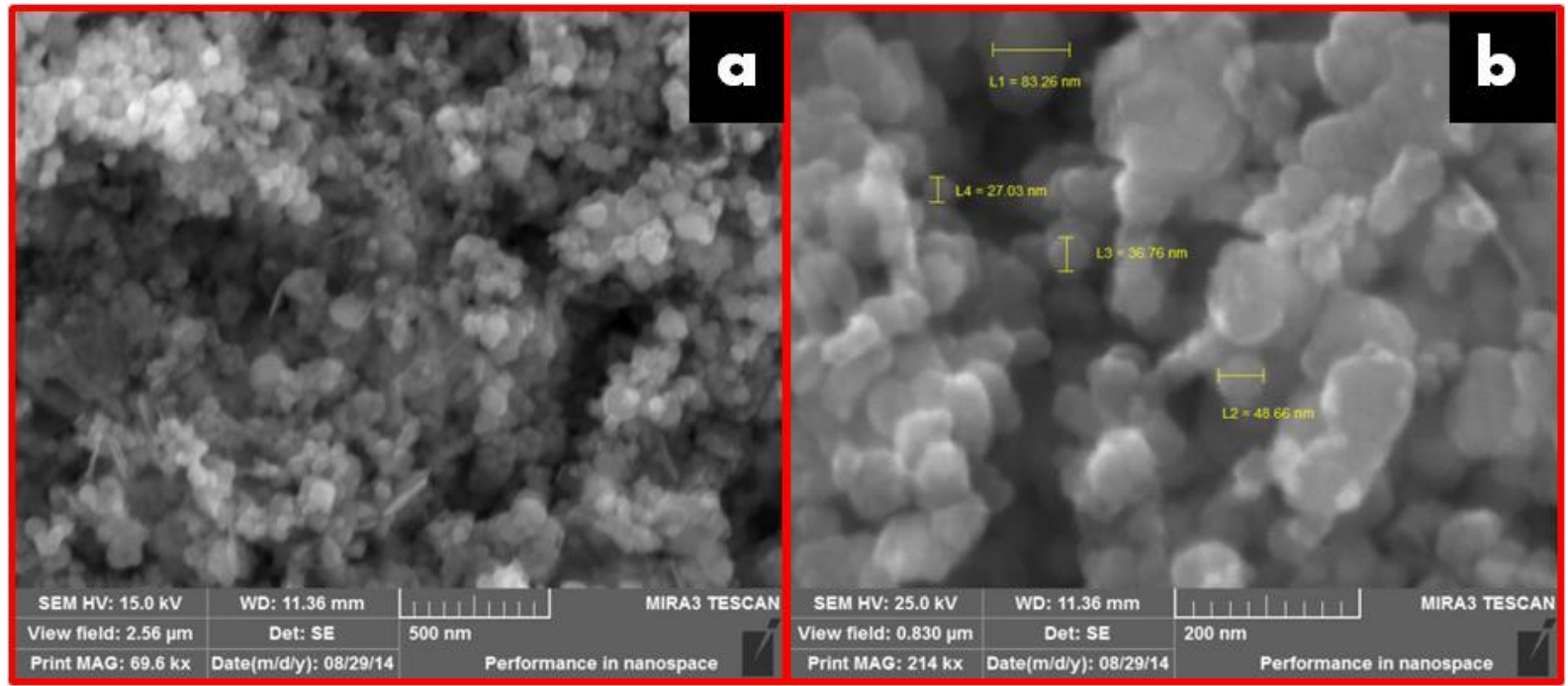

Fig. 3 SEM images of sample A: (a) at low magnification and (b) at high magnification. 


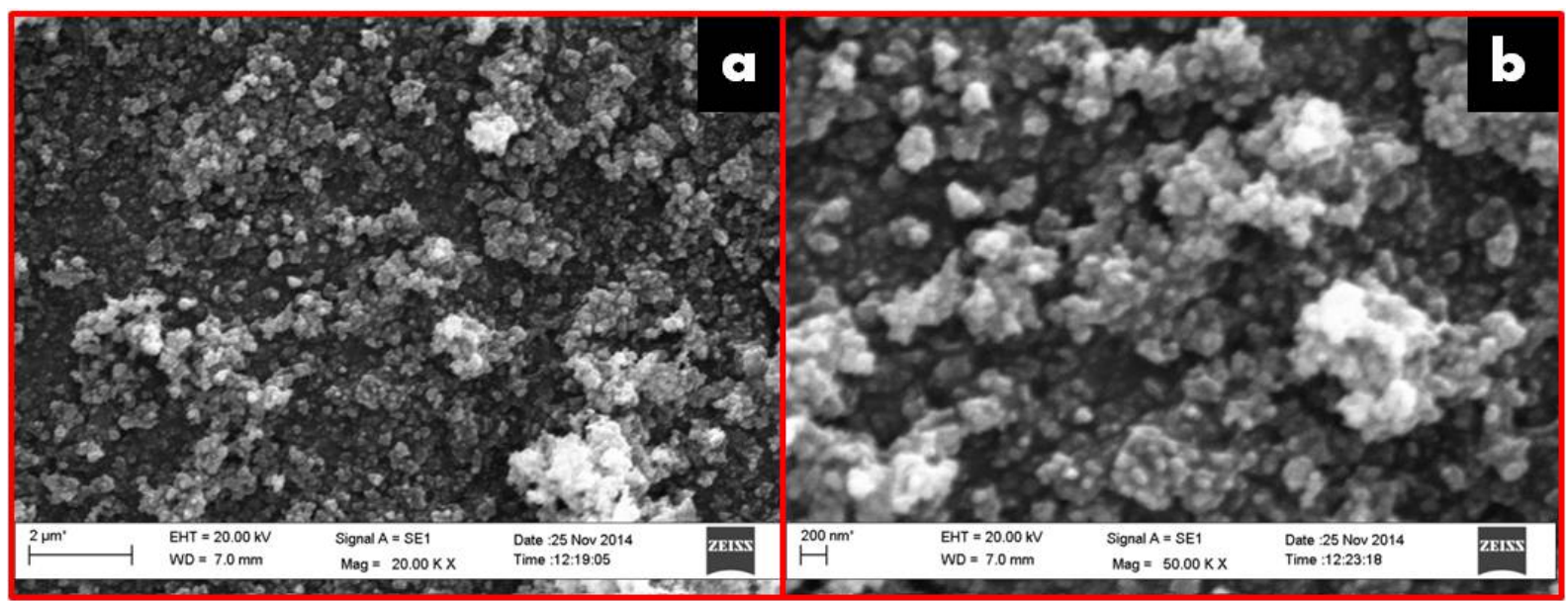

Fig. 4 SEM images of sample B: (a) at low magnification and (b) at high magnification.
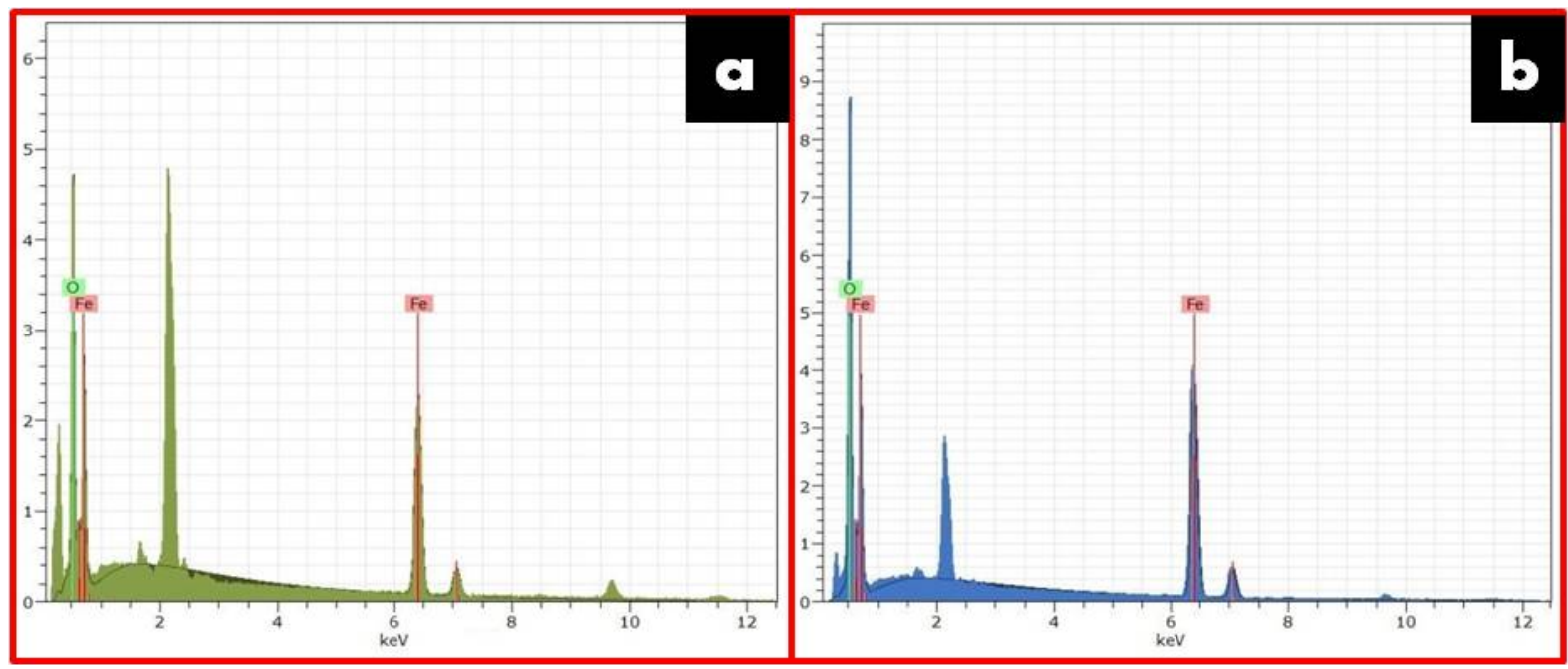

Fig. 5 SEM-EDX spectra of (a) sample A and (b) sample B.

distill water; $\mathrm{Fe}_{3} \mathrm{O}_{4}$ may be formed by an alkalization reaction of ferrous ions under a condition of excess of $\mathrm{OH}^{-}$ions [20]. Hence, the concentration of $\mathrm{OH}^{-}$ion forms one of the most important factor in synthesis procedure. It means that if we increase the concentration of $\mathrm{OH}^{-}$ions by adding $\mathrm{NaOH}$ or $\mathrm{KOH}$, it leads to better synthesis of magnetite nanoparticles.

Another approach for increasing $\mathrm{OH}^{-}$ions is by decreasing the distance between two electrodes so that $\mathrm{OH}^{-}$ions produced by the reduction of $\mathrm{H}_{2} \mathrm{O}$ at the cathode can react with $\mathrm{Fe}^{2+}$ ions to form $\mathrm{Fe}(\mathrm{OH})_{2}$. We adapt the later approach by keeping the distance of 3 to $4 \mathrm{~cm}$ approximately for different set of reactions.

There is chain of reactions which take place in the formation of magnetite nanoparticles. At each and every step, the change in color of the solution was noted.

At the beginning of the experiment, when the potential difference is zero, the solution is transparent. As the reaction started, the iron anode was oxidized:

$$
\mathrm{Fe} \rightarrow \mathrm{Fe}^{2+}+2 \mathrm{e}^{-}
$$

And the reduction of water occurs at the cathode according to the following reaction:

$$
2 \mathrm{H}_{2} \mathrm{O}+2 \mathrm{e}^{-} \rightarrow \mathrm{H}_{2}+2 \mathrm{OH}^{-}
$$

Then, solution color changes to yellow-brown and marks the formation of $\mathrm{Fe}(\mathrm{OH})_{2}$, due to the arrival of $\mathrm{OH}^{-}$ions produced at the cathode to the anode by diffusion, creating the basic medium necessary for the reaction.

$$
\mathrm{Fe}^{2+}+2 \mathrm{OH}^{-} \rightarrow \mathrm{Fe}(\mathrm{OH})_{2}
$$




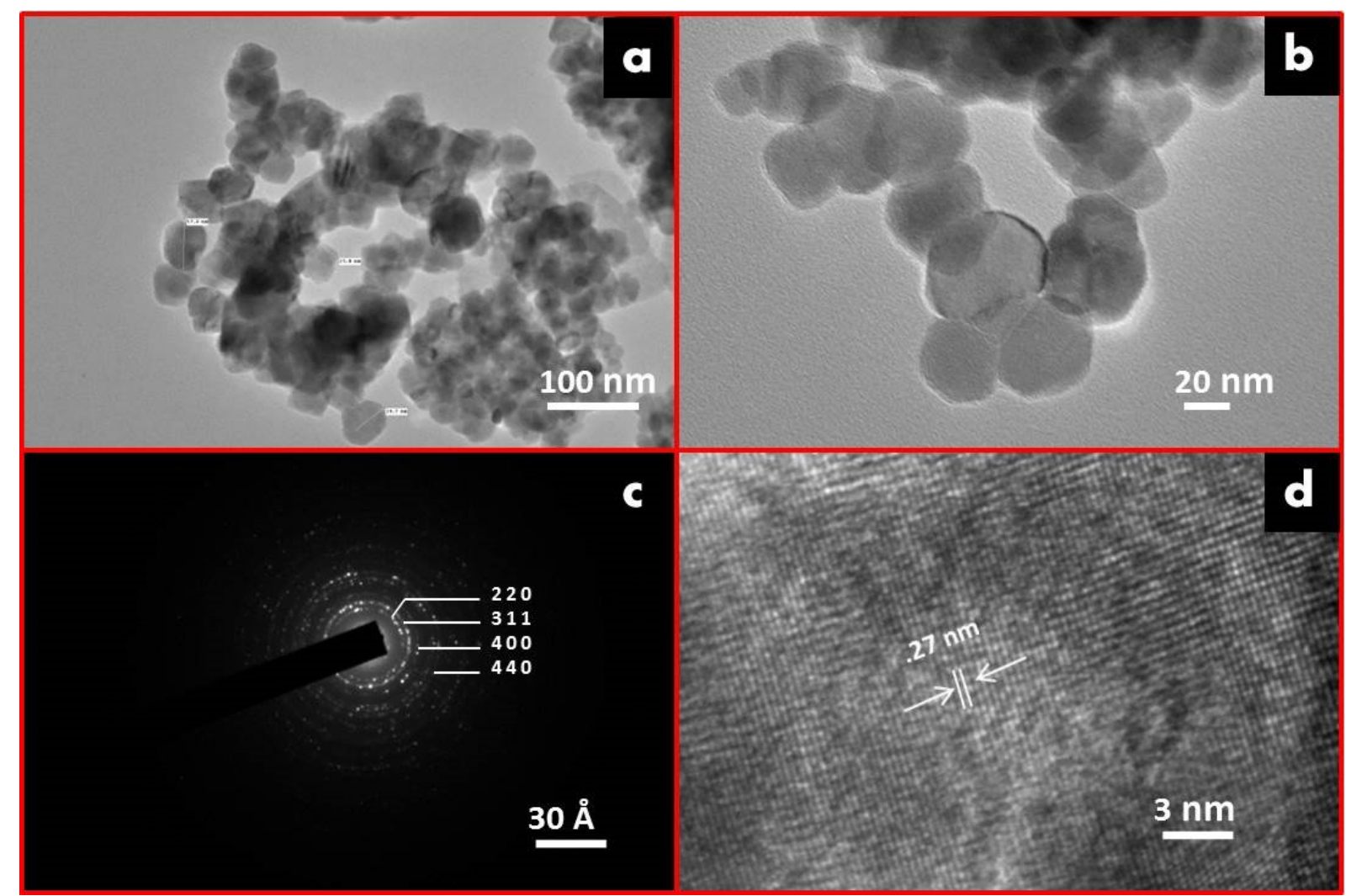

Fig.6 TEM bright field images of sample A: (a) at low magnification, (b) at high magnification, (c) corresponding selected area diffraction pattern and (d) High resolution TEM image.

After the formation of ferrous hydroxide, the color changes to reddish-brown, this slightly marks the presence of $\mathrm{FeOOH}$ which comes from:

$3 \mathrm{Fe}(\mathrm{OH})_{2}+1 / 2 \mathrm{O}_{2} \rightarrow \mathrm{Fe}(\mathrm{OH})_{2}+2 \mathrm{FeOOH}+\mathrm{H}_{2} \mathrm{O}$ (4)

And finally, the precipitate becomes black indicating the formation of magnetite nanoparticles by the reaction between ferrous hydroxide and $\mathrm{FeOOH}$ :

$$
\mathrm{Fe}(\mathrm{OH})_{2}+\mathrm{FeOOH} \rightarrow \mathrm{Fe}_{3} \mathrm{O}_{4}+2 \mathrm{H}_{2} \mathrm{O}
$$

For better yield of $\mathrm{Fe}_{3} \mathrm{O}_{4}$, current density and supporting electrolyte plays an important role. It was observed that at higher current density, the $\mathrm{Fe}_{3} \mathrm{O}_{4}$ nanoparticles formation rate comes out to be faster. In our studies, we had also taken into account the role of supporting electrolyte and used sodium chloride $(\mathrm{NaCl})$ for that purpose. At higher concentrations of sodium chloride $(\mathrm{NaCl})$, the synthesis rate was faster and vice versa.

\section{Conclusions}

Magnetite nanoparticles with average particle size of
$50 \mathrm{~nm}$ at operating voltage of $2 \mathrm{~V} \mathrm{DC}$ and $100 \mathrm{~nm}$ at operating voltage of $4 \mathrm{~V}$ DC have been successfully synthesized. The achieved nanoparticles are mono-dispersed and crystalline in nature with face-centered cubic structure. With increase in operating voltages, the particle size increases and vice versa.

\section{Acknowledgment}

This work was supported by the Special Centre for Nanoscience, Jawaharlal Nehru University, New Delhi. The author would like to thank Prof. H. B. Bohidar for his motivation in the study conducted. Author would also like to thank Advanced Instrumentation Research Facility, Jawaharlal Nehru University, New, for SEM, EDX and TEM characterizations.

\section{References}

[1] Laurent, S., Forge, D., Port, M., Roch, A., Robic, C. and Elst, L. V. et al. 2008. "Magnetic Iron Oxide 
Nanoparticles: Synthesis, Stabilization, Vectorization, Physicochemical Characterizations, and Biological Applications." Chem. Rev 108 (6): 2064-110.

[2] Tartaj, P., Morales, M. P., Verdaguer, S. V., Carre no, T. G. and Serna, C. J. 2003. "The Preparation of Magnetic Nanoparticles for Applications in Biomedicine." J. Phys. D: Appl. Phys 36: 182-97.

[3] Ying, T. Y., Yiacoumi, S. and Tsouris, C. 2002. "An Electrochemical Method for the Formation of Magnetite Particles." Journal of Dispersion Science and Technology 23: 569-76.

[4] Wu, S., Ozaki, M., Uddin, M. A. and Sasaoka, E. 2008. "Development of Iron-Based Sorbents for $\mathrm{Hg}^{0}$ Removal from Coal Derived Fuel Gas: Effect of Hydrogen Chloride." Fuel 87 (4-5): 451-9.

[5] Li, C., Shen, Y., Jia, M., Sheng, S., Adebajo, M. O. and Zhu, H. 2008. "Catalytic Combustion of Formaldehyde on Gold/Iron-Oxide Catalysts." Catal. Commun. 9 (3): 355-61.

[6] Liu, Q., Cui, Z. M., Ma, Z., Bian, S. W., Song, W. G. and Wan, L. J. 2007. "Morphology Control of $\mathrm{Fe}_{2} \mathrm{O}_{3}$ Nanocrystals and their Application in Catalysis. Nanotech. 18 (38): 37-45.

[7] Mohan, D. and Pittmang, C. U. Jr. 2006. "Activated Carbons and Low Cost Adsorbents for Remediation of Tri- and Hexavalent Chromium from Water.” Journal of Hazardous Materials 137 (2): 762-811.

[8] Mohan, D. and Pihman, C. U. 2007. "Arsenic Removal from Water/Wastewater Using Adsorbents-A Critical Review." J. Hazard. Mater. 142 (1-2): 1-53.

[9] Meg, J. H., Yang, G. Q., Yan, L. M. and Wang, X. Y. 2005. J. Dyes Pigments 66: 109-115.

[10] Cornell, R. M. and Schwertmann, U. 1996. "The Iron Oxides. Structure, Properties, Reaction, Occurrence and Uses in: VCH." Germany and USA.

[11] Hernando, A., de la Venta, J., Sampedro, B., Pinel, E. F., Merino, J. M. and Crespo, P. et al. 2005. "Mag-Netic
Properties of Metallic Nanoparticles.” 2nd NanoSpain Worshop, Barcelona, Spain.

[12] Wang, J., Yas, M., Xu, G., Cui, P. and Zhao, J. 2009. "Synthesis of Monodispersed Nanocrystals of High Crystallinity Magnetite Through Solvothermal Process." Matter. Chem. Phys. 113: 6-9.

[13] Ni, S., Wang, X., Zhou, G., Yang, F., Wang, J. and Wang, Q. et al. 2009. "Hydrothermal Synthesis of $\mathrm{Fe}_{3} \mathrm{O}_{4}$ Nanoparticles and its Application in Lithium Ion Battery." J. Mater. Letter 63: 2701-3.

[14] He, K., Xu, C. Y., Zhen, L. and Shao, W. Z. 2007. "Hydrothermal Synthesis and Characterization of Single-Crystalline $\mathrm{Fe}_{3} \mathrm{O}_{4}$ Nanowires with High Aspect Ratio and Uniformity." J. Mater. Letter 61: 3159-62.

[15] Chen, D., Ni, S. and Chen, Z. 2007. "Synthesis of $\mathrm{Fe}_{3} \mathrm{O}_{4}$ Nanoparticles by Wet Milling Iron Powder in a Planetary Ball Mill." J. China Particuology 5: 357-8.

[16] Tang, N. J., Zhang, W., Jiang, H. Y., Wu, X. L., Lio, W. and Du, Y. W. 2004. "Nanostructured Magnetite $\left(\mathrm{Fe}_{3} \mathrm{O}_{4}\right)$ Thin Films Prepared by Sol-Gel Method." J. Magnet. Magnet. Mater. 282: 92-5.

[17] Chiu, W. S., Radiman, S., Abdullah, M. H., Khiew, P. S., Huang, N. M. and Shukor, R. A. 2007. "Synthesis and Characterization of $\mathrm{ZnO}$ and $\mathrm{Fe}_{3} \mathrm{O}_{4}$ Nanocrystals from Oleat-Based Organometallic Compounds.” J. Mater. Chem. Phys. 106: 231-5.

[18] Cabreraa, L., Gutierreza, S., Menendezb, N., Moralesc, M. P. and Herrastib, P. 2008. "Magnetite Nanoparticles: Electrochemical Synthesis and Characterization." Electrochimica Acta 53 (8): 3436-41.

[19] Karami, H. and Chidar, E. 2012. "Pulsed-Electrochemical Synthesis and Characterizations of Magnetite Nanorods." Int. J. Electrochem. Sci. 7: 2077-90.

[20] Olowe, A. A. and Genin, J. M. R. 1991. "The Mechanism of Oxidation of Ferrous Hydroxide in Shulphated Aqueous Media: Importance of the Initial Ratio of the Reactants." Corros. Sci. 32: 965-84. 